\title{
PENILAIAN QUALITY FUNCTION DEPLOYMENT UTILITAS KENDARAAN DAN FASILITAS PEMBERHENTIAN ANGKUTAN KOTA MAKASSAR
}

\author{
Ahmad Hanafie ${ }^{1}$, Hammada Abbas ${ }^{2}$, Lawalenna Samang ${ }^{3}$ dan Sumarni Hamid ${ }^{4}$ \\ ${ }^{1}$ Program Doktor Teknik Sipil, Universitas Hasanuddin, Jl. Perintis Kemerdekaan KM-10 \\ Email: ahmadhanafie@yahoo.co.id. \\ ${ }^{2}$ Jurusan Teknik Mesin, Universitas Hasanuddin, Jl. Perintis Kemerdekaan, Km. 10 \\ Email:hammadaabbas@yahoo.co.id \\ ${ }^{3}$ Jurusan Teknik Sipil, Universitas Hasanuddin, Jl. Perintis Kemerdekaan KM-10 \\ Email: samang_l@yahoo.com \\ ${ }^{4} J u r u s a n$ Teknik Sipil, Universitas Hasanuddin, Jl. Perintis Kemerdekaan KM-10 \\ Email: marni_hamidaly@yahoo.com
}

\begin{abstract}
ABSTRAK
Quality Function Deployment (QFD) merupakan pendekatan interaktif sektor industri untuk menilai kebutuhan konsumen sebelum perancangan produksinya dilakukan, elemen dasar pengukuran QFD menekankan perancangan produk dan jasa guna kebutuhan dan kepuasan konsumen termasuk menganalisa kinerja produk untuk memenuhi kepuasan konsumen dan mengurangi banyaknya perubahan desain. Penelitian ini menimplementasikan konsepsi tersebut untuk mengkaji pengembangan atribut-atribut pelayanan yang diprioritaskan untuk meningkatkan kualitas pelayanan basis pengguna. Pengumpulan data kualitatif pengguna angkutan umum di Kota Makassar dilakukan secara persepsional dan pengukuran geometri angkutan umum dan infrastruktur pemberhentian. Hasil penilaian atribut-atribut pelayanan perlunya prioritas perbaikan terhadap; fasilitas halte memiliki nilai perioritas 4.354 , material tempat duduk dengan nilai perioritas 3.680, akses naik turun dengan nilai perioritas 3.678, keempat perbaikan tinggi kursi dengan nilai perioritas 3.511, kelima penambahan dan perbaikan trotoar dengan nilai perioritas 3.395. Peningkatkan kualitas pelayanan yang sesuai harapan pengguna yaitu adanya tempat area parkir dan fasilitas ideal bagi kendaraan dan penumpang agar kendaraan tidak acak menaik turunkan penumpang. Tata kursi dan material disesuaikan dengan nilai ergonomi agar penumpang nyaman saat menggunakan kendaraan. Guna kemudah pengguna kendaraan untuk akses naik turun kendaraan maka trotoar tingginya disesuaikan dengan dimensi tubuh pengguna.
\end{abstract}

Kata kunci: Utilitas kendaraan, Fasilitas Pemberhentian, Nilai Ergonomis, Quality Function Deployment

\section{PENDAHULUAN}

Pelayanan jasa angkutan umum ditinjau dari dimensi prasarana, sarana, dan sistem operasi memiliki atribut-atribut berupa; waktu, ongkos, keamanan, kenyamanan, dan pelayanan sehingga ekspektasi dan persepsi pengguna jasa angkutan umum lebih dapat terwakilkan dan terakomodasi. Konsep Quality Function Deployment (QFD), pendekatan ini merupakan metode terstruktur yang umum digunakan dalam proses perencanaan dan pengembangan produk dalam rangka penetapan spesifikasi kebutuhan dan keinginan konsumen serta mengevaluasi suatu produk dalam memenuhi kebutuhan dan keinginan konsumen (Cohen, 1995). Suatu organisasi yang mengimplementasikan QFD secara tepat dapat meningkatkan pengetahuan rekayasa, produktivitas dan kualitas, mengurangi biaya, mengurangi waktu pengembangan produk serta perubahanperubahan rekayasa seiring dengan kemajuan jaman dan permintaan konsumen.

Permasalahan mendasar utilitas kendaraan umum di Kota Makassar terindetifikasikan bahwa dari 140 kendaraan yang diobservasi tidak mempunyai kesamaan tentang ukuran bahkan rentang tidak mempunyai fasilitas yang mestinya ada sepert; akses turun naik seperti tangga pertama, tangga kedua, lebar pintu, lebar tangga dan hanggar pintu. Tata kursi yang meliputi tinggi kursi, panjang kursi pertam, panjang kursi kedua dan tinggi sandaran. Infrastruktur jalan belum difasilitasi kriteria design geometri ideal dan fasilitas pemberentian memadai seperti; kursi tunggu tidak ideal, rambu lalu lintas kurang memadai sehingga pengendara kendaraan umum menaikan dan menurunkan penumpang dimana saja yang tentunya mengenai keamanan. Fasilitas infrastruktur tersebut dari tinjauan keamanan dan kenyamanan iluminasi jalan kurang sesuai dengan harapan pengguna kendaraan. 
Penelitian ini dimaksudkan untuk melakukan asesmen terhadap kualitas pelayanan kendaraan umum (angkotan mikrolet) di Kota Makassar ditinjauan dari aspek ergonomis utilitas kenderaan dan fasilitas pemberhentiannya. Asesmen terhadap utilitas kendaraan umum dan fasilitas pemberhentian kendaraan angkutan umum dari aspek aman dan nyaman didasarkan atribut pengukuran QFD. Pengembangan atribut-atribut pelayanan yang berkeseuaian perbaikan kualitas pelayanan dikritisi sejalan dengan keinginan pengguna.

\section{TINJAUAN PUSTAKA}

\section{Isu strategi sarana dan prasarana}

Pemberhentian bus pada kota-kota besar di dunia, halte bus salah satu ruang publik di kota adalah tempat dimana bus transit dan turun naiknya penumpan. Setiap berhenti memiliki dua arah, yaitu pintu gerbang yang transit dan untuk pejalan kaki. Di Kota Denver, halte bus angkutan mall memiliki kursi bergerak, orang-orang dapat mengatur tempat duduk mereka sendiri secara santai saat menunggu bus. Kota Morella Mexico pada tempat pemberhentian dan halte bus penumpang dapat mengambil camilan mangga segar atau nanas. Kota Portland tempat pemberhentian bus di kota ini memiliki sistem informasi yang baik sistem transit yaitu setiap rute diberi logo khusus kode warna untuk masing-masing arah, membantu orang menavigasi jaringan bus serta dapat menunjukkan jadwal bus. Kota Los Angeles di pemberhentian bus di Los Angeles, penumpang harus menunggu di bangku-bangku iklan. Ada rasa kekwatiran terhadap perlindungan diri dimana terlalu dekat dengan lalu lintas. Dan di Kota Barcelona tempat pembentian bus dibuat setipis mungkin dan transparan dan di desain shelter yang indah dan penumpang dapat duduk dengan nyaman. (Suisman, Doug).

\section{Konsep quality function deployment kendaraan umum}

Dalam penerapan QFD, digunakan format matriks untuk menangkap hal-hal yang penting terhadap proses perencanaan suatu produk. Matriks ini disebut House Of Quality (HOQ). Defenisi HOQ adalah matriks perencanaan produk yang menggambarkan kebutuhan pelanggan, target perusahaan dan evaluasi produk pesaing. HOQ terdiri dari beberapa komponen seperti terlihat pada gambar 1.

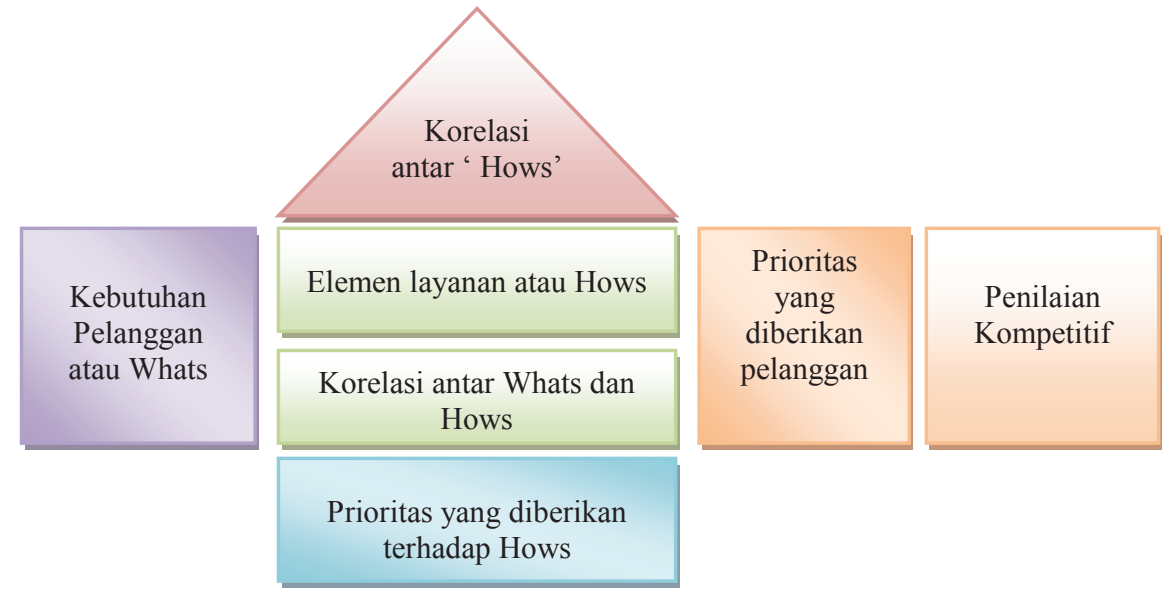

Gambar 1. House of Quality

Komponen-komponen dalam HOQ adalah Whats adalah keinginan/kebutuhan pelanggan, Hows adalah kebutuhan-kebutuhan dari desain atau 'bahasa teknis' produk/layanan jasa, Matriks korelasi: menjelaskan hubungan antara whats dan hows. Hubungan ini dapat digambarkan dengan simbol (kuat, cukup, lemah), Matriks korelasi antar Hows, menggambarkan hubungan antar hows. Korelasi ini dapat dibedakan menjadi korelasi positif dan negative, Prioritas yang diberikan pelanggan terhadap kebutuhannya. Selain itu ada pula prioritas terhadap hows, dan penilaian kompetitif adalah penilaian produk/layanan jasa organisasi dengan organisasi pesaingnya.

Keistimewaan HOQ adalah komponen-komponennya dapat dimodifikasi sesuai dengan keinginan organisasi. Setelah membuat HOQ dasar, matriks-matriks tambahan dibuat untuk dapat menyampaikan kebutuhan/keinginan pelanggan kesemua tahap yang ada diorganisasi. Matriks-matriks tambahan ini adalah: design, deployment, manufacturing planning, transportasi dan production planning. 


\section{Mengembangkan rumah kualitas}

Cohen (1995) menyatakan dalam membuat Rumah Kualitas (House of Quality) urutan yang paling berguna adalah:

Matriks Kebutuhan Pelanggan, tahap ini meliputi: Memutuskan siapa pelanggannya, Mengumpulkan data kualitatif berupa keinginan dan kebutuhan pelanggan, Menyusun kebutuhan dan keinginan tersebut, Membuat diagram afinitas. Setelah melakukan pengumpulan data pelanggan dalam jumlah besar dan masih sulit diatur maka diperlukan adanya diagram afinitas.

Matriks Perencanaan, tahap ini bertujuan untuk: Mengukur tingkat kebutuhan-kebutuhan pelanggan, Dalam mengukur tingkat kebutuhan pelanggan dilakukan dengan cara debat dari tim pelaksana atau dengan riset preferensi pasar dengan melakukan survei, Menetapkan tujuan-tujuan performansi kepuasan. Hal ini dilakukan untuk memenuhi masing-masing kebutuhan konsumen.

Respon Teknis, Tahap ini mempunyai transformasi dari kebutuhan-kebutuhan konsumen yang bersifat non teknis menjadi data yang bersifat teknis guna memenuhi kebutuhan-kebutuhan tersebut, Menentukan Hubungan Respon Teknis Dengan Kebutuhan Konsumen.

Tahap ini menentukan seberapa kuat hubungan antara respon teknis dengan kebutuhan-kebutuhan pelanggan. Hubungan keduanya dapat berupa hubungan yang sangat kuat, sedang, tidak kuat atau tidak ada hubungan keduanya.

Korelasi Teknis, Bagian ini memetakan hubungan dan kepentingan antara karakterstik kualitas pengganti atau respon teknis. Hal ini dilakukan agar dapat dilihat apabila suatu respon teknis saling mempengaruhi dengan respon teknis lainnya dalam proses produksi, dan juga dapat diusahakan agar tidak terjadi botleneck.

\section{METODE PENELITIAN}

Penelitian dilakukan di Kota Makassar, pemilihan Kota Makassar dengan pertimbangan bahwa Kota tersebut mempunyai angkutan kota yang cukup besar sekitar 4113 kendaraan dari 17 trayek namun, dari segi utilitas kendaraan belum optimal apalagi kendaraan umum tidak ada keseragaman yang ada pada fasilitas kendaraan seperti akses naik turun, hangar pintu, tata kursi, pengkondisian kenyamanan dan Fasilitas Pmberhentian hampir seluruh kota Makassar tidak difungsikan dan tempat pemberhentian pun hanya beberapa saja itu tidak difungsikan dengan optimal.

\section{Rancangan survei dan validitas data penelitian}

Data diperoleh dengan metode survei, observasi dan wawancara. Data terdiri dari 2 macam yaitu data primer dan data sekunder. Data primer berupa hasil pengamatan dan hasil kuesioner terhadap pengguna kendaraan, sedangkan data sekunder diperoleh melalui literatur. Kuesioner dibagikan kepada responden anak-anak sekolah, mahasiswa, Pegawai Negeri maupun Swasta dan penumpang umum dengan metode sampel untuk mengetahui tingkat kepentingan setiap karakteristik pengguna kendaraan. Dalam pegambilan data tingkat kepentingan, kepuasan, dan kepuasan yang diharapkan menggunakan skala Likert.

\section{Tahap membangun rumah kualitas}

Pada tahap membangun rumah kualitas ada lima tahap perlu dilakukan yaitu, Voice Of Customer, Matriks Perencanaan, Penentuan Respon Teknis, Penentuan Matriks Hubungan dan Prioritas, Analisa dan Interpretasi.

Tabel 2. Atribut Pelayanan kendaraan umum (customer needs)

\begin{tabular}{lll}
\hline & Customer Requirement (WHATs) \\
\hline Utilitas & Keamanan & Akses naik turu \\
\hline Utilitas & Keamanan & Hanggar Pintu \\
\hline Utilitas & Kenyamanan & Tata Kursi \\
\hline Utilitas & Kenyamanan & Pencahayaan \\
\hline Utilitas & Kenyamanan & Sirkulasi Udara \\
\hline Utilitas & Kenyamanan & Bau-bauan \\
\hline Utilitas & Kenyamanan & Panas dalam ruangan \\
\hline Utilitas & Kenyamanan & Warna dalam ruangan \\
\hline Tempat Pemberhentian & Keamanan & Trotoar \\
\hline Tempat Pemberhentian & Keamanan & Halte \\
\hline Tempat Pemberhentian & Keamanan & Rambu-Rambu Lalulintas \\
\hline
\end{tabular}


Tabel 3. Respon Tekniks (HOWs)

\begin{tabular}{cl}
\hline No. & Respon Teknik $(\mathrm{HOWs})$ \\
\hline 1 & Kualitas Material yang digunakan \\
\hline 2 & Perbaikan tinggi kursi \\
\hline 3 & Perbaikan material tempat duduj \\
\hline 4 & Perbaikan akses naik \\
\hline 6 & Perbaikan pada hangar \\
\hline 7 & Penambahan lampu dalam kendaraan \\
\hline 8 & Perbaikan sirkulasi udara dalam kendaraa \\
\hline 9 & Adanya area dan fasilitas pada halte \\
\hline 10 & Perbaikan penerangan jalanan \\
\hline 11 & Perbaikan/penambahan rambu-rambu lalulintas \\
\hline 12 & Adanya ruang hijau / taman kota \\
\hline
\end{tabular}

\section{HASIL DAN PEMBAHASAN}

Dalam penelitian atribut-atribut tersebut dikelompokkan dalam suatu tabel, tabel tesebut adalah dapat dilihat pada Tabel 4. Hasil atribut pelayanan yang diinginkan pengguna kendaraan umum (customer need). Atribut-atribut tersebut merupakan kebutuhan pengguna angkutan umum yang ada Kota Makassar, diantaranya tingkat kepentingan, tingkat kepuasan yang dirasakan dan tingkat kepuasan yang diharapkan.

Tabel 4. Hasil Atribut Pelayanan kendaraan umum (customer needs)

\begin{tabular}{|c|l|c|c|c|}
\hline \multirow{2}{*}{ No. } & \multirow{2}{*}{ Keterangan Atribut } & \multicolumn{3}{|c|}{ Customer Statisfaction } \\
\cline { 3 - 5 } & Akses naik turun & $\begin{array}{c}\text { Tingkat } \\
\text { Kepentingan }\end{array}$ & $\begin{array}{c}\text { Tingkat } \\
\text { Dirasakan }\end{array}$ & $\begin{array}{c}\text { Tingkat } \\
\text { Diharapkan }\end{array}$ \\
\hline 1 & 4.528 & 2.267 & 4.713 \\
\hline 2 & Hanggar pintu & 4.307 & 2.353 & 4.680 \\
\hline 3 & Tata kursi & 4.646 & 2.467 & 4.667 \\
\hline 4 & Pencahayaan & 4.292 & 2.520 & 4.427 \\
\hline 5 & Sirkulasi Udara & 3.910 & 2.553 & 4.400 \\
\hline 6 & Bau-bauan & 3.917 & 2.147 & 4.220 \\
\hline 7 & Panas dalam ruamgam & 3.681 & 1.960 & 4.153 \\
\hline 8 & Warna dalam ruangan & 3.514 & 2.393 & 4.300 \\
\hline 9 & Trotoar & 4.313 & 2.433 & 4.553 \\
\hline 10 & Halte & 4.319 & 2.367 & 4.460 \\
\hline 11 & Rambu-rambu lalulintas & 4.563 & 2.740 & 4.487 \\
\hline 12 & Taman yang indah dan hijau & 4.306 & 2.373 & 4.293 \\
\hline 13 & Iluminansi jalan & 4.286 & 2.353 & 4.547 \\
\hline 14 & Tarif & 4.396 & 2.380 & 4.152 \\
\hline
\end{tabular}

Dari hasil penelitian responden tingkat kepentingan tersebut seperti terlihat pada Tabel 4, keempatbelas atribut menyatakan persepsi responden pada skala 3,514 - 4,646 yang artinya cukup penting dan sangat penting utilitas kendaraan dan tempat pemberhentian. Pada tingkat kepuasan responden menyatakan persepsi keempatbelas atribut pada skala 1,960 -2,740 yang artinya kurang memuaskan dalam dalam menggunakan kendaraan umum. Sedangkang kepuasan yang diharapkan responden dengan skala 4,152 4,713 yang artinya responden mengharapkan adanya perbaikan pada utilitas kendaraan dan fasilitas pemberhentian. 


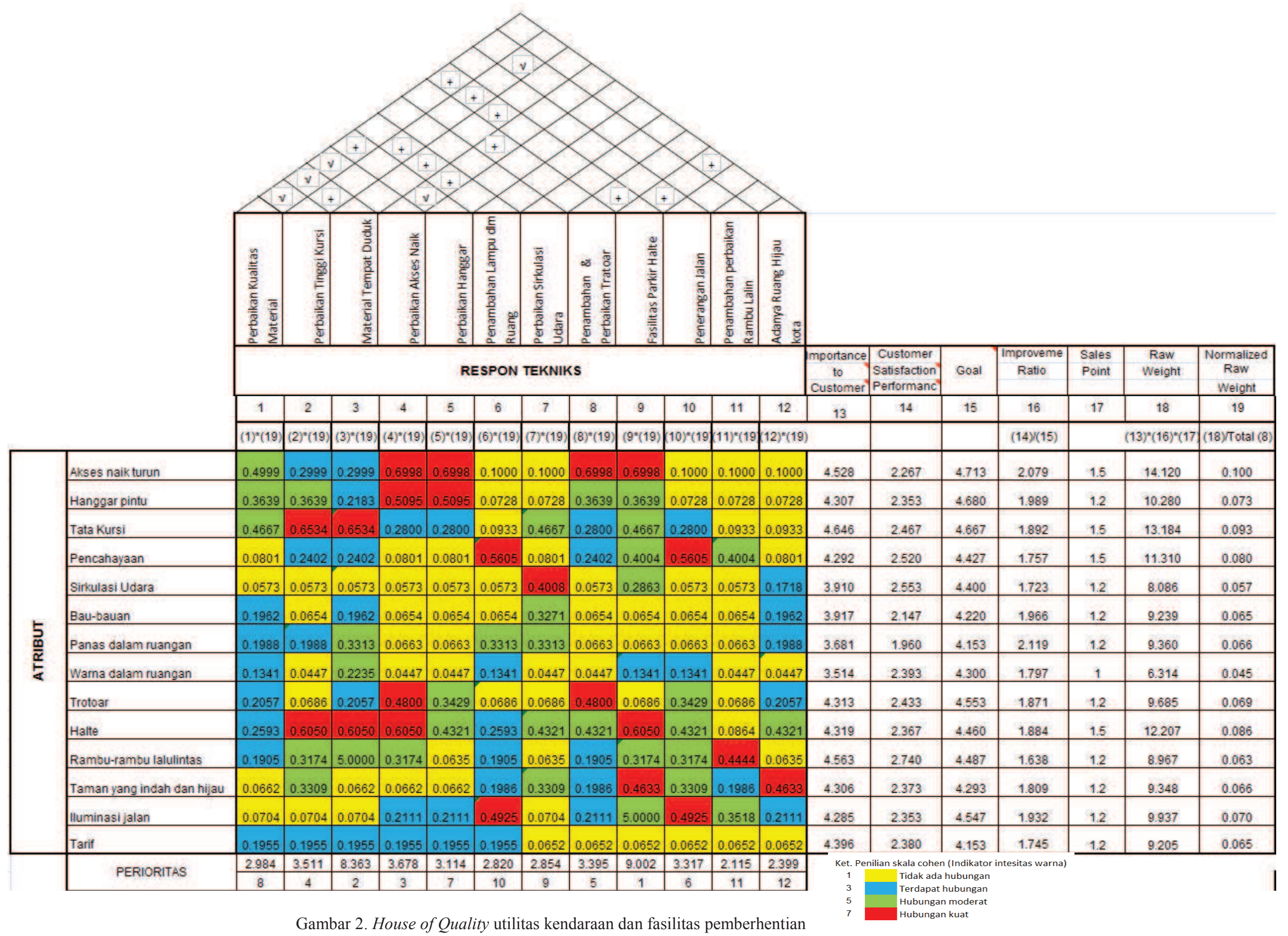


Gambar 2. House of quality diperoleh prioritas pertama adalah perlu perbaikan area parkir halte dengan nilai perioritas 4,354, kedua material tempat duduk dengan nilai perioritas 3,680, ketiga perbaikan akses naik turun dengan nilai perioritas 3,678, keempat perbaikan tinggi kursi dengan nilai perioritas 3,511, kelima penambahan dan perbaikan trotoar dengan nilai perioritas 3,395, keenam penerangan jalan dengan nilai perioritas 3,317, ketujuh perbaikan hangar dengan nilai perioritas 3,114, kedelapan perbaikan kualitas material dengan nilai perioritas 2,984, kesepuluh penambahan lampu dalam ruang dengan nilai perioritas 2,820, kesebelas penambahan perbaikan rambu lalu lintas dengan nilai perioritas 2,461 dan keduabelas adanya ruang hijau kota dengan nilai perioritas 2,399.

Dalam meningkatkan kualitas pelayanan yang sesuai dengan keinginan pengguna yaitu perlu pertama adanya tempat area parkir dan fasilitas yang ideal bagi kendaraan angkutan kota dan penumpang agar kendaraan tidak sebarangan menaik turunkan penumpang, kedua tata kursi dan material yang digunakan sesuai dengan nilai ergonomi agar penumpang merasakan kenyamanan saat menggunakan kendaraan. Ketiga untuk memudahkan pengguna kendaraan untuk akses naik turun kendaraan maka troktoar tingginya disesuaikan dengan dimensi tubuh pengguna. Keempat penerangan lampu jalan sesuai dengan aturan yang ada yaitu minimal 70 lux, agar pengguna kendaraan angkutan kota merasa aman saat malam hari, dan kelima adalah penambahan rambu-rambu lalu lintas serta ukuran yang standar supaya pengguna kendaraan dapat memperoleh informasi yang jelas.

\section{KESIMPULAN}

Atribut-atribut pelayanan yang diprioritaskan pertama adalah perlu perbaikan area parkir halte dengan nilai perioritas 4,354, kedua material tempat duduk dengan nilai perioritas 3,680, ketiga perbaikan akses naik turun dengan nilai perioritas 3,678, keempat perbaikan tinggi kursi dengan nilai perioritas 3,511, kelima penambahan dan perbaikan trotoar dengan nilai perioritas 3,395, keenam penerangan jalan dengan nilai perioritas 3,317, ketujuh perbaikan hangar dengan nilai perioritas 3,114, kedelapan perbaikan kualitas material dengan nilai perioritas 2,984, kesepuluh penambahan lampu dalam ruang dengan nilai perioritas 2,820, kesebelas penambahan perbaikan rambu lalu lintas dengan nilai perioritas 2,461 dan keduabelas adanya ruang hijau kota dengan nilai perioritas 2,399.

Peningkatkan kualitas pelayanan yang sesuai dengan keinginan pengguna yaitu perlu pertama adanya tempat area parkir dan fasilitas yang ideal bagi kendaraan angkutan kota dan penumpang agar kendaraan tidak sebarangan menaik turunkan penumpang, kedua tata kursi dan material yang digunakan sesuai dengan nilai ergonomi agar penumpang merasakan kenyamanan saat menggunakan kendaraan. Ketiga untuk memudahkan pengguna kendaraan untuk akses naik turun kendaraan maka troktoar tingginya disesuaikan dengan dimensi tubuh pengguna. Keempat penerangan lampu jalan sesuai dengan aturan yang ada yaitu minimal 70 lux, agar pengguna kendaraan angkutan kota merasa aman saat malam hari, dan kelima adalah penambahan rambu-rambu lalu lintas serta ukuran yang standar supaya pengguna kendaraan dapat memperoleh informasi yang jelas.

\section{DAFTARA PUSTAKA}

Ahmad Hanafie, Hammada Abbas, Lawalenna Samang, Sumarni Hamid, (2014), Kajian Utilitas Kendaraan dan Fasilitas Pemberhentian Angkutan Kota Yang Bernilai Ergonomi, Publikasi Ilmiah Proposal Penelitian S3 Teknik Sipil Unhas, Vol. April 2014, ISSN: 2087-7986.

Ahmad Hanafie, Hammada Abbas, Lawalenna Samang, Sumarni Hamid, (2014), Kajian Utilitas Kendaraan Angkutan Kota Yang Bernilai Ergonomi. Proceding Seminar Nasional Teknologi Industri II ATIM 2014, ISBN 978-602-14822-1-6. hal. 307-310.

Ahmad Hanafie, Hammada Abbas, Lawalenna Samang, Sumarni Hamid, (2015), "Facilities Studi Termination Of The Value Of City Transport Ergonomics". Conference Programme The $2^{\text {nd }}$ Makassar Internasional Conference On Civil Engineering, ISBN 978-979-530-134-9.. pp. 705-709.

Ahmad Hanafie, Hammada Abbas, Lawalenna Samang, Sumarni Hamid, (2015), Kajian Utilitas Kendaraan Angkutan Kota Makassar Yang Bernilai Ergonomi, Publikasi Ilmiah Hasil Penelitian S3 Teknik Sipil Unhas, Vol. Agustus 2015, ISSN: 2087-7986.

Cohen L, (1995), Quality Function Deployment: How to Make QFD Work for You Addison Wesley-Publishing Company, Massachusets

Geetam Tiwari, (2002), “Urban Transport Priorities", Cities, Vol. 19,2, hal. 95 - 103.

Muchtar Ginting, (2011), "Analisa Permasalahan Komponen Tempat Tidur Pasien Dengan Metode QFD”, Jurnal Austenit, Vol. 3, Nomor 2.

Mukti Advani, Geetam Tiwari, (2006), "Review of Capacity Improvement Strategies for Bus transit service", Indian Journal of Transport Management, Oktober - Desember 2006.

Ngudi Tjahjono, (1996), Ancangan Sistematik dalam Pengembangan Sistem Transportasi Kota, Seminar regional Sstrategi pengembangan Transportasi," di Fakultas Teknik Univ. Widyagama Malang.

Ranjay M, Shrestha and Edmund J. Zolnik, (2013), "Eliminating Bus Stops: Evaluating Changges in Operations, Emissions and Coverage", Journal of Public Transportation, Vol 16, No. 2, hal. 2913. 
Susilowati, Achmad Wicaksono, Tunjung W. Suharso, Kajian Kinerja, (2011), “Angkutan Umum Dengan Metode Quality Function Deployment (QFD) pada Kawasan Industri Marmer di Kabupaten Tulungagun”, Jurnal Rekayasa Sipil, Vol 5, No. 3- 2011, hal 191-200

Suisman, Doug, (1997), "Bus Stops as Urban Places (streets: Old Paradigm, New Ivestment)", Journal Issue, Places, 11 (2).

Sritomo Wignjosoebroto, (2008), Ergonomi, Studi Gerak \& waktu. Penerbit Guna widya, Jakarta.

Sudjana, (1989), Metoda Statistika, penerbit Tarsito, Bandung.

Yuni Hermawan, (2010), "Studi Ergonomi Perancangan dan Pengembangan Produk Tongkat Lansia dengan Metode Quality Function Deployment (QFD)”, Jurnal Rekayasa, Volume 7, Nomor 1 Juli 2010, hal. 97-109

Sonya Marliana, Rini Dharmastiti", (2008), "Integrasi Servqual dan QFD untuk Meningkatkan Kualitas Layanan Angkutan Massa Trans Jogya”, Proceding Seminar Nasional Aplikasi Sain dan Teknologi 2008-IST AKPRIND Yogyakarta, hal. 110-114. 
Prosiding Konferensi Nasional Teknik Sipil 9 (KoNTekS 9) Komda VI BMPTTSSI - Makassar, 7-8 Oktober 2015 